\title{
연속혈당모니터를 활용한 혈당 관리
}

\section{강양교}

가톨릭대학교 부천성모병원 간호부

\section{Glucose Management Using Continuous Glucose Monitors}

\section{Yanggyo Kang}

Department of Nursing, The Catholic University of Korea, Bucheon St. Mary's Hospital, Bucheon, Korea

\section{Abstract}

In the Diabetes Care Guidelines of the Korean Diabetes Association in 2015, the use of continuous glucose monitoring in patients with type 1 diabetes who undergo multiple insulin therapy or insulin pump therapy is helpful in controlling blood sugar and monitoring blood glucose level when fluctuation is high or hypoglycemia is frequent. Recently, the American Diabetes Association published in the 2019 Standard of Care in Diabetes in the new diabetes technology part the criteria for use and methods of the continuous blood glucose meter. Continuous and real-time blood glucose meters emphasize the importance of education prior to use. In particular, the real-time blood glucose meter is a useful device for prevention of hypoglycemia in type 1 diabetes in children and adults. The purpose of this study is to summarize the contents of the continuous blood glucose measurement part of the 2019 Standard of Care in Diabetes.

Keywords: Continuous glucose monitoring, Diabetes mellitus, Guideline

\author{
서론 \\ 당뇨병 환자의 혈당을 파악하기 위하여 여러 가지 방법 \\ 들이 사용되고 있으며, 그 중 일반적으로는 현재 시점의
}

혈당을 알 수 있는 자가 혈당 측정(self-monitoring blood glucose, $\mathrm{SMBG}$ )과 지난 2 3개월간 혈당의 평균을 알 수 있는 당화혈색소( $\mathrm{HbA1c})$, 현재의 $\mathrm{SMBG}$ 의 한계점을 보완 하기 위한 방법인 연속 혈당 모니터링(continuous glucose 
monitoring, CGM)이 있다. CGM은 5분마다 당 수치를 저 장하여 식사 중에, 잠을 자고 있을 때, 일상생활 중에서 변 하고 있는 혈당을 알 수 있고, 당화혈색소와 $\mathrm{SMBG}$ 로 알아 내기 힘든 저혈당과 고혈당, 혈당 변동성을 확인할 수 있어 중증 저혈당을 인지하지 못하는 환자뿐만 아니라[1] 잘 조 절되지 않는 불안정 당뇨병, 엄격한 혈당 조절이 요구되는 임신성 당뇨병, 당뇨병성 케톤산증에 이환될 가능성이 높은 경우, 당뇨조절 프로그램을 처음 계획하거나 시행 - 평가하 는 경우 등 다양한 상황의 당뇨병 환자들에게 도움을 줄 수 있다. 2015년 대한당뇨병학회의 당뇨병진료지침에서도 다 회인슐린요법이나 인슐린 펌프 치료를 하는 제 1 형 당뇨병 환자에서 연속 혈당 모니터의 사용은 혈당 조절에 도움이 되며, 혈당 변동폭이 크거나 저혈당이 빈번한 경우 혈당조 절을 감시하는 방법으로 $\mathrm{CGM}$ 을 사용할 수 있다고 하였다 [2].

최근 미국 당뇨병학회(American Diabetes Association, ADA)에서 발표한 The 2019 Standard of Medical Care in Diabetes에서는 이번에 신설된 당뇨병 테크놀로지 부분에 서 CGM에 대한 사용 대상, 방법, 투여기준을 제시하였다. 연속 및 실시간 혈당 모니터링은 사용에 앞서 교육의 중요 성을 강조했다. 특히 실시간 혈당 모니터링은 소아와 성인 의 1 형 당뇨병 환자를 위한 장비로, 저혈당 예방을 위한 유 용한 장비로 규정하였다[3].

이에 The 2019 Standard of Medical Care in Diabetes 의 CGM 부분의 내용을 요약, 정리해 보고자 한다.

\section{본론}

\section{1. 연속 혈당 모니터}

1) 권고안

- 센서강화펌프치료가 저혈당증이나 심각한 저혈당의 증 가 없이 혈당 조절을 개선하기 위하여 어린이, 청소년 및 성인에서 사용을 고려할 수 있다. 지속적인 모니터링 의 이점은 장치의 지속적인 사용에 대한 순응과 관련이
있다. 〔A]

- CGM을 할 때 최적의 연속 혈당 모니터 구현 및 지속적 인 사용을 위해서는 당뇨병 교육, 훈련 및 지원이 필요 하다. [E]

- 성공적인 연속 혈당 모니터 사용을 위해서는 보험 재정 을 통해 지속적으로 이용할 수 있어야 한다. [E]

$\mathrm{CGM}$ 은 간질 포도당(혈당 포도당과 매우 관련이 있음)을 측정한다. CGM 장치에는 두 가지 유형이 있다. 대부분의 $\mathrm{CGM}$ 장치는 실시간 CGM이며 혈당 수준을 지속적으로 보 고하고 저혈당 및 고혈당 경보를 포함한다. 다른 유형의 장 치는 성인용으로만 승인된 $\mathrm{CGM}$ (isCGM)으로, 간헐적으 로 검사하며 경보가 없고 자동 경고가 있는 시스템보다 비 용이 적게 드는 것으로 되어 있다.

\section{2. 청소년에 대한 연속 혈당 모니터 사용}

1) 권고안

- 혈당 조절을 개선하고 저혈당 위험을 줄이는 데 도움이 되는 추가적인 도구로서 1형 당뇨병 어린이와 청소년에 게 매일 여러 차례의 주사나 지속적인 피하 인슐린 주사 를 사용하는지 여부와 관계없이 실시간 CGM을 고려해 야 한다. 지속적인 모니터링의 이점은 장치의 지속적인 사용에 대한 순응과 관련이 있다. [B]

성인과 소아 환자의 자료를 함께 분석했을 때, 무작위 대조군연구(randomized controlled trial, $\mathrm{RCT}$ )에서의 $\mathrm{CGM}$ 사용은 $\mathrm{HbAlc}$ 수준의 감소와 관련이 있다[4-6]. 그 러나 Juvenile Diabetes Research Foundation continuous glucose monitoring (JDRF-CGM) 연구에서 연령대(8 14 세 및 15 24세)로 청소년을 분석한 결과 CGM 순응도가 낮아서 $\mathrm{HbAlc}$ 의 변화가 없는 것으로 나타났다[7]. 두 소아 집단에서 $\mathrm{RCT}$ 자료를 2 차 분석한 결과 주당 6 일 이상 센서 를 사용하는 사람들은 혈당 조절이 개선되었다[8]. CGM의 성공에 중요한 요소 중 하나는 매일 착용하는 것이다[9].

저혈당 예방을 목표로 한 RCT는 저혈당에 걸린 시간을 약 $40 \%$ 줄이고 하루에 1 단계 저혈당의 발생 횟수를 줄이는 
측면에서 경미한 유의한 감소를 입증했다[10].

\section{3. 성인에서의 실시간 연속 혈당 모니터 사용}

1) 권고안

- 집중적인 인슐린 요법과 함께 실시간으로 연속 혈당을 모니터링하는 것이 혈당 목표를 충족시키지 못하는 제 1 형 당뇨병 성인의 $\mathrm{Alc}$ 를 낮추는 유용한 도구이다. 〔A]

- 실시간 CGM은 저혈당을 인지하지 못하거나 저혈당 에 피소드가 있는 사람들에게 유용한 도구가 될 수 있다. [B]

- 실시간 $\mathrm{CGM}$ 은 최대한의 효과를 위해 가능한 한 매일 사용해야 한다. [A]

- 제1형 당뇨병 임산부에서 당화혈색소와 neonatal outcomes를 개선시키기 위해 실시간 CGM이 효과적으 로 사용될 수 있다. [B]

- 저혈당 발생을 예방하고 중증도를 줄이기 위하여 저혈 당 위험이 높은 제 1 형 당뇨병 성인에게 센서 자동 증강 펌프 치료가 고려될 수 있다. [B]

일반적으로 $\mathrm{HbA1c}$ 감소는 기준 $\mathrm{HbA} 1 \mathrm{c}$ 가 더 높은 연구 에서 나타났다. 일일 다회 인슐린 주사요법(multiple daily injection, MDI) 환자의 CGM 효과를 평가한 제1형 당뇨 병 성인 2 건의 연구에서 $\mathrm{Alc}$ 의 유의한 감소가 있었는데 $-0.6 \%$ [11], 다른 하나는 $-0.43 \%$ [12]였다. 제1형 당 뇨병이 있는 소규모의 교육 수준이 낮은 성인에서 수행된 작은 연구에서 $\mathrm{Alc}$ 의 감소는 보이지 않았다[13]. JDRF$\mathrm{CGM}$ 연구의 성인 하위 집단에서는 인슐린 펌프 요법으로 주로 치료를 받은 환자에서 $\mathrm{A} 1 \mathrm{c}$ 가 $-0.53 \%$ [7]로 유의하게 감소했다. CGM 장치를 착용할 때 더 나은 순응도는 혈당 조절의 개선 가능성을 더 크게 나타냈다[14].

저혈당 발작 감소가 주요 결론이었던 성인 연구에서 제 1 형 당뇨병 환자의 MDI 또는 지속 피하 인슐린 주입요법 (continuous subcutaneous insulin infusion, CSII)에서 유의한 감소가 나타났다[15]. 저혈당 발생 위험이 높은 환 자의 한 연구에서 저혈당의 모든 수준의 비율이 감소했다.
$\mathrm{MDI}$ 에 대한 제2형 당뇨병 환자의 연구(DIAMOND)에서 복수 일일 주사 및 지속적인 혈당 모니터링은 저혈당의 감 소를 보여주지 못했다[16]. 인슐린 유무에 관계없이 경구약 을 복용하는 제 2 형 당뇨병 환자에 대한 연구에서는 저혈당 발생률이 감소하지 않았다[17]. CGM은 저혈당에 대한 인 식이 없거나 저혈당증이 빈번한 인슐린 치료 환자에게 특히 유용할 수 있지만, 심각한 저혈당의 지속적인 감소는 보이 지 않았다[5,6].

1 개의 잘 설계된 RCT는 MDI 또는 CSII에서 임신한 제 1 형 당뇨병이 있는 성인 여성에서 $\mathrm{HbA1c}$ 수치가 감소한 것 을 보여주었다[18]. 어머니가 임신 중에 CGM을 사용했을 때 신생아 결과가 더 좋았다[19].

\section{4. 간헐적 연속 혈당 모니터 사용}

1) 권고안

- 간헐적으로 스캔되는 연속 혈당 모니터는 빈번한 혈당 검사를 필요로 하는 성인 당뇨병 환자에서 자가 혈당 측 정 대신 사용할 수 있다. [C]

isCGM (때로는 플래시 CGM이라고도 함)은 피부 아래 에 삽입된 $0.4 \mathrm{~mm}$ 두께의 필라멘트를 통해 간질액 내 포도 당을 측정하는 $\mathrm{CGM}$ 이다. isCGM의 개인용 버전에는 센서 를 통해 센서를 스캔한 후 실시간 혈당값을 표시하는 수신 기가 있다. 캐나다 의약품안전청은 isCGM의 성능과 정확 성, 저혈당, $\mathrm{A} 1 \mathrm{c}$ 에 대한 영향, 환자 만족도 및 삶의 질에 대 한 기존 데이터를 검토하여 빈번한 테스트가 필요한 환자에 게 특히 $\mathrm{SMBG}$ 를 대체할 수 있다고 결론지었다[20].

\section{결론}

당뇨병 환자의 합병증을 예방하고 혈당 조절을 적절하게 하기 위해서는 환자의 혈당 상태를 정확하게 파악할 수 있 는 것이 무엇보다 중요하다. 기존의 $\mathrm{SMBG}$ 의 단점을 보완 한 CGM은 혈당을 한눈에 알아볼 수 있어 당뇨병 환자의 혈 당 조절을 개선시키고 저혈당의 감소로 삶의 질을 향상시키 
는 데 도움이 된다. 이번 $\mathrm{ADA}$ 권고로 최근 사용이 늘어나 고 있는 당뇨병 관련 첨단 의료기기에 관해 당뇨병 환자들 의 요구에 응답할 수 있도록 당뇨병 교육자 스스로의 공부 가 필요하겠고, 이에 따라 환자들이 장비 사용에 앞서 정확 한 교육을 받을 수 있어야겠다.

\section{REFERENCES}

1. Hirsch IB. Hypoglycemia and the hypoglycemic unawareness syndrome. Diabetes Technol Ther 2000;2 Suppl 1:S81-7.

2. Korean Diabetes Association. Treatment guideline for diabetes 2015. Seoul: Korean Diabetes Association; 2015.

3. American Diabetes Association. 7. Diabetes technology: Standards of Medical Care in Diabetes-2019. Diabetes Care 2019;42(Suppl 1):S71-80.

4. Battelino T, Conget I, Olsen B, Schütz-Fuhrmann I, Hommel E, Hoogma R, Schierloh U, Sulli N, Bolinder J; SWITCH Study Group. The use and efficacy of continuous glucose monitoring in type 1 diabetes treated with insulin pump therapy: a randomised controlled trial. Diabetologia 2012;55:3155-62.

5. Deiss D, Bolinder J, Riveline JP, Battelino T, Bosi E, Tubiana-Rufi N, Kerr D, Phillip M. Improved glycemic control in poorly controlled patients with type 1 diabetes using real-time continuous glucose monitoring. Diabetes Care 2006;29:2730-2.

6. O'Connell MA, Donath S, O'Neal DN, Colman PG, Ambler GR, Jones TW, Davis EA, Cameron FJ. Glycaemic impact of patient-led use of sensor-guided pump therapy in type 1 diabetes: a randomised controlled trial. Diabetologia 2009;52:1250-7.

7. Juvenile Diabetes Research Foundation Continuous Glucose Monitoring Study Group, Tamborlane WV, Beck RW, Bode BW, Buckingham B, Chase HP, Clemons R,
Fiallo-Scharer R, Fox LA, Gilliam LK, Hirsch IB, Huang ES, Kollman C, Kowalski AJ, Laffel L, Lawrence JM, Lee J, Mauras N, O'Grady M, Ruedy KJ, Tansey M, Tsalikian E, Weinzimer S, Wilson DM, Wolpert H, Wysocki T, Xing D. Continuous glucose monitoring and intensive treatment of type 1 diabetes. N Engl J Med 2008;359:1464-76.

8. Juvenile Diabetes Research Foundation Continuous Glucose Monitoring Study Group, Beck RW, Buckingham B, Miller K, Wolpert H, Xing D, Block JM, Chase HP, Hirsch I, Kollman C, Laffel L, Lawrence JM, Milaszewski K, Ruedy KJ, Tamborlane WV. Factors predictive of use and of benefit from continuous glucose monitoring in type 1 diabetes. Diabetes Care 2009;32:1947-53.

9. Juvenile Diabetes Research Foundation Continuous Glucose Monitoring Study Group. Effectiveness of continuous glucose monitoring in a clinical care environment: evidence from the Juvenile Diabetes Research Foundation continuous glucose monitoring (JDRF-CGM) trial. Diabetes Care 2010;33:17-22.

10. Battelino T, Phillip M, Bratina N, Nimri R, Oskarsson P, Bolinder J. Effect of continuous glucose monitoring on hypoglycemia in type 1 diabetes. Diabetes Care 2011;34:795-800.

11. Riddlesworth T, Price D, Cohen N, Beck RW. Hypoglycemic event frequency and the effect of continuous glucose monitoring in adults with type 1 diabetes using multiple daily insulin injections. Diabetes Ther 2017;8:947-51.

12. Lind M, Polonsky W, Hirsch IB, Heise T, Bolinder J, Dahlquist S, Schwarz E, Ólafsdóttir AF, Frid A, Wedel H, Ahlén E, Nyström T, Hellman J. Continuous glucose monitoring vs conventional therapy for glycemic control in adults with type 1 diabetes treated with multiple daily insulin injections: the GOLD randomized clinical trial. JAMA 2017;317:379-87.

13. Sequeira PA, Montoya L, Ruelas V, Xing D, Chen V, Beck 
R, Peters AL. Continuous glucose monitoring pilot in low-income type 1 diabetes patients. Diabetes Technol Ther $2013 ; 15: 855-8$.

14. Tumminia A, Crimi S, Sciacca L, Buscema M, Frittitta L, Squatrito S, Vigneri R, Tomaselli L. Efficacy of real-time continuous glucose monitoring on glycaemic control and glucose variability in type 1 diabetic patients treated with either insulin pumps or multiple insulin injection therapy: a randomized controlled crossover trial. Diabetes Metab Res Rev 2015;31:61-8.

15. Bolinder J, Antuna R, Geelhoed-Duijvestijn P, Kröger J, Weitgasser R. Novel glucose-sensing technology and hypoglycaemia in type 1 diabetes: a multicentre, nonmasked, randomised controlled trial. Lancet 2016; 388:2254-63.

16. Beck RW, Riddlesworth TD, Ruedy K, Ahmann A, Haller S, Kruger D, McGill JB, Polonsky W, Price D, Aronoff S, Aronson R, Toschi E, Kollman C, Bergenstal R; DIAMOND Study Group. Continuous glucose monitoring versus usual care in patients with type 2 diabetes receiving multiple daily insulin injections: a randomized trial. Ann Intern Med 2017;167:365-74.

17. Ehrhardt NM, Chellappa M, Walker MS, Fonda SJ,
Vigersky RA. The effect of real-time continuous glucose monitoring on glycemic control in patients with type 2 diabetes mellitus. J Diabetes Sci Technol 2011;5:668-75.

18. Feig DS, Donovan LE, Corcoy R, Murphy KE, Amiel SA, Hunt KF, Asztalos E, Barrett JFR, Sanchez JJ, de Leiva A, Hod M, Jovanovic L, Keely E, McManus R, Hutton EK, Meek CL, Stewart ZA, Wysocki T, O'Brien R, Ruedy K, Kollman C, Tomlinson G, Murphy HR; CONCEPTT Collaborative Group. Continuous glucose monitoring in pregnant women with type 1 diabetes (CONCEPTT): a multicentre international randomised controlled trial. Lancet 2017;390:2347-59.

19. Beck RW, Riddlesworth T, Ruedy K, Ahmann A, Bergenstal R, Haller S, Kollman C, Kruger D, McGill JB, Polonsky W, Toschi E, Wolpert H, Price D; DIAMOND Study Group. Effect of continuous glucose monitoring on glycemic control in adults with type 1 diabetes using insulin injections: the DIAMOND randomized clinical trial. JAMA 2017;317:371-8.

20. Palylyk-Colwell E, Ford C. Flash glucose monitoring system for diabetes. Available from: https://www.ncbi. nlm.nih.gov/books/NBK476439 (updated 2017 Jun 01). 